\title{
Dynamic Subsidy Method for Congestion Management in Distribution Networks
}

\author{
Huang, Shaojun; Wu, Qiuwei
}

Published in:

IEEE Transactions on Smart Grid

Link to article, DOI:

10.1109/TSG.2016.2607720

Publication date:

2016

Document Version

Peer reviewed version

Link back to DTU Orbit

Citation (APA):

Huang, S., \& Wu, Q. (2016). Dynamic Subsidy Method for Congestion Management in Distribution Networks. IEEE Transactions on Smart Grid, 9(3), 2140 - 2151. https://doi.org/10.1109/TSG.2016.2607720

\section{General rights}

Copyright and moral rights for the publications made accessible in the public portal are retained by the authors and/or other copyright owners and it is a condition of accessing publications that users recognise and abide by the legal requirements associated with these rights.

- Users may download and print one copy of any publication from the public portal for the purpose of private study or research.

- You may not further distribute the material or use it for any profit-making activity or commercial gain

- You may freely distribute the URL identifying the publication in the public portal

If you believe that this document breaches copyright please contact us providing details, and we will remove access to the work immediately and investigate your claim. 


\title{
Dynamic Subsidy Method for Congestion Man- agement in Distribution Networks
}

\author{
Shaojun Huang, Student Member, IEEE, Qiuwei Wu, Senior Member, IEEE
}

\begin{abstract}
Dynamic subsidy (DS) is a locational price paid by the distribution system operator (DSO) to its customers in order to shift energy consumption to designated hours and nodes. It is promising for demand side management and congestion management. This paper proposes a new DS method for congestion management in distribution networks, including the market mechanism, the mathematical formulation through a two-level optimization, and the method solving the optimization by tightening the constraints and linearization. Case studies were conducted with a one node system and the Bus 4 distribution network of the Roy Billinton Test System (RBTS) with high penetration of electric vehicles (EVs) and heat pumps (HPs). The case studies demonstrate the efficacy of the DS method for congestion management in distribution networks. Studies in this paper show that the DS method offers the customers a fair opportunity to cheap energy prices and has no rebound effect.
\end{abstract}

Index Terms-- Congestion management, distribution system operator (DSO), dynamic subsidy, electric vehicle (EV), heat pump (HP).

\section{NOMENCLATURE}

Parameters

$A_{i, t, t_{-}} \in R^{m_{i} \times m_{i}}$ coefficient matrix, describe the relations between the power consumption and temperature change of the household

$B_{i, t} \in R^{m_{i} \times m_{i}}$ coefficient matrix of the quadratic term

$C_{a} \quad$ heat capacity of the inside air

$C_{s} \quad$ heat capacity of the house structure (walls, etc.)

$D \in R^{n_{L} \times n_{d}} \quad$ power transfer distribution factor (PTDF)

$E_{i} \in R^{n_{d} \times m_{i}}$ customer to load bus mapping matrix

$F_{t} \in R^{n_{L}} \quad$ line loading limit of active power

$K \quad$ outside temperature

$K^{a} \quad$ house inside temperature

$K^{s} \quad$ structure temperature

$K_{i, t}^{a, \min } \in R^{m_{i}}$ lower temperature limit

$K_{i, t}^{a, \max } \in R^{m_{i}}$ upper temperature limit

$M \quad$ a big constant number

$N_{B} \quad$ set of aggregators

$N_{T} \quad$ set of planning periods

The work is supported by the EU Seventh Framework Programme (FP7) through the 'Ideal Grid for All (IDE4L)' project.

S. Huang, Q. Wu are with the Center for Electric Power and Energy (CEE), Department of Electrical Engineering, Technical University of Denmark (DTU), 2800 Kgs. Lyngby, Denmark (e-mail: shuang@elektro.dtu.dk; qw@elektro.dtu.dk).

\begin{tabular}{|c|c|}
\hline$N_{L}$ & set of lines \\
\hline$N_{d}$ & set of demand bus \\
\hline$Q^{e}$ & thermal energy produced by HP \\
\hline$S_{t}^{1}$ & solar irradiation to the inside air \\
\hline$S_{t}^{2}$ & solar irradiation to the structure \\
\hline$\underline{V}$ & voltage lower limit \\
\hline$V_{0}$ & $\begin{array}{l}\text { voltage at node } 0 \text {, the secondary side of the high } \\
\text { voltage transformer }\end{array}$ \\
\hline$Y_{L L}$ & $\begin{array}{l}\text { the matrix obtained by removing the first row and } \\
\text { column of the nodal admittance matrix }\end{array}$ \\
\hline$Z$ & the inverse matrix of $Y_{L L}$ \\
\hline$a_{t, t_{-}}$ & coefficients between power and temperature \\
\hline$c_{t}$ & baseline price: energy price plus fixed cost, such \\
\hline$d_{i, t} \in R^{m_{i}}$ & $\begin{array}{l}\text { as grid tariff, tax } \\
\text { discharging power of EVs due to driving }\end{array}$ \\
\hline$e_{i}^{\min } \in R^{m_{i}}$ & lower limit of the state of charge (SOC) level \\
\hline$e_{i}^{\max } \in R^{m_{i}}$ & upper limit of the SOC level \\
\hline$e_{i, 0} \in R^{m_{i}}$ & initial SOC level \\
\hline$k_{1}$ & $\begin{array}{l}\text { heat transfer coefficient (HTC) between the in- } \\
\text { side and the outside of the household }\end{array}$ \\
\hline$k_{2}$ & HTC between the inside and the house structure \\
\hline$k_{3}$ & HTC between the house structure and the outside \\
\hline$p_{i, t}^{\min } \in R^{m_{i}}$ & lower charging power limit of EVs \\
\hline$p_{i, t}^{\max } \in R^{m_{i}}$ & upper charging power limit of EVs \\
\hline$\hat{p}_{i}^{\min } \in R^{m_{i}}$ & lower power limit of HPs \\
\hline$\hat{p}_{i}^{\max } \in R^{m_{i}}$ & upper power limit of HPs \\
\hline$p_{t}^{c}$ & active conventional power consumption at each \\
\hline$q_{t}^{c}$ & $\begin{array}{l}\text { load point } \\
\text { reactive conventional power consumption at each }\end{array}$ \\
\hline$u_{i, t} \in R^{m_{i}}$ & $\begin{array}{l}\text { load point } \\
\text { initial temperature }\end{array}$ \\
\hline$\alpha$ & coefficient, for reducing price sensitivity \\
\hline$\beta$ & price sensitivity \\
\hline \multicolumn{2}{|l|}{ Variables } \\
\hline$p$ & charging power of EV \\
\hline$p_{i, t} \in R^{m_{i}}$ & charging power of EVs of one aggregator \\
\hline$\hat{p}_{i, t} \in R^{m_{i}}$ & power consumption of HPs of one aggregator \\
\hline
\end{tabular}




$\begin{array}{ll}r_{t} \in R^{n_{d}} & \begin{array}{l}\text { regulation price } \\ S_{t} \in C^{n_{d}}\end{array} \\ & \begin{array}{l}\text { total apparent power consumption at each load } \\ \text { point }\end{array} \\ \lambda_{t} \in R^{n_{L}} & \begin{array}{l}\text { Lagrange multiplier (LM) of line loading limit } \\ \text { constraint }\end{array} \\ \mu_{i, t}^{+} \in R^{m_{i}} & \text { LM of SOC upper limit constraint } \\ \mu_{i, t}^{-} \in R^{m_{i}} & \text { LM of SOC lower limit constraint } \\ \hat{\mu}_{i, t}^{+} \in R^{m_{i}} & \text { LM of upper temperature limit constraint } \\ \hat{\mu}_{i, t}^{-} \in R^{m_{i}} & \text { LM of lower temperature limit constraint } \\ S_{i, t}^{+} \in R^{m_{i}} & \text { LM of EV charging power upper limit constraint } \\ S_{i, t}^{-} \in R^{m_{i}} & \text { LM of EV charging power lower limit constraint } \\ \hat{\varsigma}_{i, t}^{+} \in R^{m_{i}} & \text { LM of HP power upper limit constraint } \\ \hat{\varsigma}_{i, t}^{-} \in R^{m_{i}} & \text { LM of HP power lower limit constraint } \\ \rho_{t} & \text { LM of load equation } \\ \omega_{t} & \text { LM of voltage constraint }\end{array}$

Other Symbols

$m_{i} \quad$ the number of customers of aggregator $i$

$n_{*} \quad$ cardinality of $N_{*}$, i.e. $n_{*}=\left|N_{*}\right|$

$\|*\|_{1} \quad$ L-1 norm of vector *

$\{*\}_{j} \quad$ j-th element of vector *

\section{INTRODUCTION}

$\mathrm{R}$ ENEWABLE energies, distributed generation (DG), and flexible demands such as electric vehicles (EVs) and heat pumps (HPs) will be extensively deployed in future power systems. Potential congestion problems might occur in distribution networks due to the simultaneous charging or discharging of flexible demands. It has drawn the attention of distribution system operators (DSOs), manufacturers and researchers. In addition to reinforcing the distribution network through their long term planning, DSOs can use smart coordination methods to avoid or mitigate the congestions, including direct and indirect (market-based) control [1], multi-agent system methods [2], [3] and probabilistic congestion management methods [4], [5].

References [6]-[9] have proposed the dynamic tariff (DT) concept, which shares the same key principle with the distribution locational marginal price (DLMP) concept in [10], [11]. The DT differs from the DLMP in the market features and the applications of solving congestions in distribution networks with high penetration of flexible demands. In the DT concept, the congestion management is realized in a decentralized manner. The aggregators of flexible demands independently determine their optimal energy plans of the flexible demands without explicitly considering the network constraints because they are represented by the DTs. The DT method is economically efficient for alleviating congestions in distribution networks, because only those consumers causing congestions pay the DT. However, considering the regulations of distribution networks in many countries nowadays [12], there are regulatory issues to deploy the DT method. Firstly, from the perspective of the customers, the DT method may not be a fair method, because the customers might have to accept different tariff rates because of their locations in the network. This is against the non-discrimination rules specified by the regulations. Secondly, the flexible demands that help alleviate congestions pay the DT instead of getting rewards. Similarly, the congestion pricing method in [13], the real-time pricing method in [14] and the intraday market clearing method in [15] are also against the regulation requirement, because the customers having congestions pay a high price while those not having congestions pay a low price.

A monetary incentive based method was proposed in [16] for coordinating and rescheduling the flexible demands, where the capacity limit of the distribution networks was taken into account. With this method, the flexible demands will be rewarded if they are willing to reduce the consumption during the congestion hours. However, the method to determine a proper incentive is not optimal. The authors of [16] choose the best one from a finite set of predefined incentives, however, it is not necessarily the optimal one. The rebound effect, the reduced flexible demand will cause an increase in a future period, is not considered because the method only handles one period at each execution. Another issue is that it does not consider the location of the incentives. The demand responses for solving congestions are usually needed at specific areas or nodes. Locational incentives can improve the efficiency of solving congestions because the responses of the flexible demands from uncritical areas or nodes (e.g. the upstream nodes to the congested point) have a limited effect. These issues also exist in other previous studies, such as in [17], [18].

In order to resolve the issues of the abovementioned demand response methods, this paper proposes a dynamic subsidy (DS) method to handle the potential congestion problems in distribution networks. Same as the DT method, the DS method realizes the congestion management in a decentralized manner. The DS motivates the aggregators to re-profile their energy plans such that the network constraints are respected. The DS is a timed subsidy for the next day paid by the DSO to the aggregators while the DT is a tariff collected by the DSO from the aggregators. In the DS method, the DSO provides subsidies to the aggregators who are willing to consume the energy at the designated hours, when there are available capacities predicted by the DSO. As a result, the energy consumptions at "peak" hours or potential congestion hours are under the limits.

The motivations of proposing the DS method are summarized as the follows. Firstly, like other incentive-based methods, the DS method does not have regulatory issues. The DSO normally needs an official approval from the authorities to charge new types of tariffs. However, the DSO's purchase of services from the customers does not require a special approval. Secondly, the DS determined by the DSO is always limited between zero and the maximum predicted energy price. The DT is unlimited in theory. In practice, the upper limit of the 
DT can be set, however, the efficacy of the DT method will be compromised [19]. Finally, unlike other incentive-based methods, it provides an efficient method to determine the DS without iterative information exchanges between the DSO and the aggregators. And it does not incur the rebound effect of the DS while other incentive-based DS methods do.

The main contributions of this paper include: 1) Propose the DS method for congestion management in distribution networks; 2) Propose a two-level optimization model to determine the optimal DS; check the feasibility of the two-level optimization and propose an equivalent one-level optimization that is easier to solve.

The rest of the paper is organized as follows. The DS concept, mathematical formulation of the DS method and the feasibility study are presented in Section III. The calculation of the DS through optimization is described in Section IV. The analysis and comparison of the DS method with the DT method is presented in Section V. In Section VI, case studies are presented and discussed. The paper ends with the conclusions.

\section{DS CONCEPT}

In this section, the market mechanism of the DS method for congestion management of distribution networks is presented. Afterwards, the mathematical foundation of the DS concept is described.

\section{A. Decentralized Congestion Management through the DS Concept}

The DS method for congestion management in distribution networks is based on the day-ahead energy market mechanism and can be seamlessly integrated into the day-ahead energy market (spot market in Nordic). This is the same as the DT method, except that the DS is an income for the aggregators. The DS is a price signal from the DSO to the aggregators, which implies that the DSO has only an indirect control of the aggregators. The aggregators have the freedom of choosing their own optimal energy planning for the flexible demands. And the aggregators as business units are economically rational and pursue the maximum profits. The DSO needs to predict the energy requirements of the flexible demands and determine an appropriate set of DS to motivate the aggregators to re-profile the flexible demands as wished by the DSO. In this sense, the DS method for congestion management is a decentralized control method.

The process of the decentralized congestion management by using the DS is described as follows. Firstly, the DSO obtains the flexible demand data, such as energy requirements and the availability, by its own prediction or from aggregators. The DSO also needs to collect the network information from its own sources and obtain the predicted day-ahead energy price from third parties. Secondly, a set of DS is calculated through an optimal energy plan respecting the network constraints, and the DS is published to all the aggregators before the closure of the day-ahead energy market. Thirdly, after receiving the DS, the aggregators make their own optimal plans independently with the predicted energy prices, a fixed cost (in this paper, it refers to fixed grid tariffs and tax) and the DS. At last, the aggregators submit their energy plan/bids to the day-ahead energy market.

The DSO may use the money collected from the customers through distribution grid tariffs to pay the DS. The DSO has the right to collect grid tariffs to cover the cost of operation, maintenance and reinforcement of the distribution grid. The DSO pays the DS in order to solve congestion problems, which can effectively postpone the very costly reinforcement of the grids. Therefore, the DS method is of the interest of both the DSO and the customers because all the costs are ultimately paid by the customers. This also means that the congestion, wherever it is in the distribution grid, is solved by the contribution of every customer.

\section{B. Mathematical Formulation of DS Method}

1) Formulation at the aggregator side:

At the aggregator side, the formulations of the DS and DT methods are similar. The aggregators are purely economic units without any consideration of the network constraints. They make energy plans based on the requirements of the flexible demands and the prices, including the energy price, and the fixed cost (such as grid tariffs and tax), and the DS (or DT). In both the DS and the DT methods, the aggregators use the following optimization problem to determine the energy plans of EVs and HPs in the day-ahead energy market. In this paper, home-charging EVs and HPs are considered, while other possible flexible demands such as parking-lot EVs [20] and air conditioners [21] will be studied in the future.

For aggregator $i$,

$$
\begin{array}{r}
\min _{p_{i, t}, \hat{p}_{i, t}} \sum_{t \in N_{T}} \frac{1}{2} p_{i, t}{ }^{T} B_{i, t} p_{i, t}+\left(c_{t} \mathbf{1}+E_{i}^{T} r_{t}\right)^{T} p_{i, t}+ \\
\frac{1}{2} \hat{p}_{i, t}{ }^{T} B_{i, t} \hat{p}_{i, t}+\left(c_{t} \mathbf{1}+E_{i}^{T} r_{t}\right)^{T} \hat{p}_{i, t}
\end{array}
$$

subject to,

$$
\begin{gathered}
e_{i}^{\min } \leq \sum_{t_{-} \leq t}\left(p_{i, t_{-}}-d_{i, t_{-}}\right)+e_{i 0} \leq e_{i}^{\max }, \forall \mathrm{t} \in \mathrm{N}_{t},\left(\mu_{i, t}^{-}, \mu_{i, t}^{+}\right), \\
p_{i, t}^{\min } \leq p_{i, t} \leq p_{i, t}^{\max } \quad \forall t \in N_{T},\left(\varsigma_{i, t}^{-}, \varsigma_{i, t}^{+}\right), \\
K_{i, t}^{a, \min } \leq \sum_{t_{-} \leq t} A_{i, t, t_{-}} \hat{p}_{i, t_{-}}+u_{i, t} \leq K_{i, t}^{a, \max }, \forall \mathrm{t} \in N_{T},\left(\hat{\mu}_{i, t}^{-}, \hat{\mu}_{i, t}^{+}\right), \\
\hat{p}_{i, t}^{\min } \leq \hat{p}_{i, t} \leq \hat{p}_{i, t}^{\max } \quad t \in N_{T},\left(\hat{\varsigma}_{i, t}^{-}, \hat{\varsigma}_{i, t}^{+}\right) .
\end{gathered}
$$

The regulation price $r_{t}$ in (1) can be either positive or negative. When it is positive ( $r_{t}>0, \forall t \in N_{T}$ ), it is the DT. When it is negative ( $r_{t}<0, \forall t \in N_{T}$ ), it is the DS.

Constraints (2) - (3) are from the limits of EVs. Constraint (4) represents the thermal limits of households and (5) gives the input power limits of HPs. Constraint (4) is derived from the thermal process analysis of the household and the HP as shown in the appendix.

2) Formulation at the DSO side:

At the DSO side, the formulations of the DS and DT methods are quite different. The DT method will be briefly reviewed first.

The DSO needs to determine a proper regulation price such 
that the sum of all aggregators' energy planning resulting from (1)-(5) will not exceed the network constraints. This is the key idea of the DT and DS methods. In order to determine DTs in the DT method, [8] proposed a method using the following optimization problem (6)-(14). Constraint (8) is added in this paper to represent the voltage limits based on the approximation method proposed in [22]. The DTs are calculated from the Lagrange multipliers of the line loading constraint (7) and the voltage constraint (8), or equivalently, the Lagrange multipliers of the load equation (9). Note that (10) can be inserted into (8) and be eliminated.

$$
\begin{gathered}
\min _{p_{i, t}, \hat{p}_{i, t}} \sum_{i \in N_{B}, t \in N_{T}} \frac{1}{2} p_{i, t}{ }^{T} B_{i, t} p_{i, t}+\left(c_{t} \mathbf{1}\right)^{T} p_{i, t}+ \\
\frac{1}{2} \hat{p}_{i, t}{ }^{T} B_{i, t} \hat{p}_{i, t}+\left(c_{t} \mathbf{1}\right)^{T} \hat{p}_{i, t}
\end{gathered}
$$

subject to

$$
\begin{gathered}
D \operatorname{Re}\left(s_{t}\right) \leq F_{t}, \forall t \in N_{T},\left(\lambda_{t}\right) \\
V_{0}\left(1-\frac{1}{V_{0}^{2}} \operatorname{Re}\left(Z s_{t}\right)\right) \geq \underline{V}, \forall t \in N_{T},\left(\omega_{t}\right) \\
\operatorname{Re}\left(s_{t}\right)=p_{t}^{c}+\sum_{i \in N_{B}} E_{i}\left(p_{i, t}+\hat{p}_{i, t}\right), \forall t \in N_{T},\left(\rho_{t}\right) \\
\operatorname{Im}\left(s_{t}\right)=q_{t}^{c}, \forall t \in N_{T} \\
e_{i}^{\min } \leq \sum_{t_{-} \leq t}\left(p_{i, t_{-}}-d_{i, t_{-}}\right)+e_{i, 0} \leq e_{i}^{\max }, \forall \mathrm{t} \in N_{t}, i \in N_{B}, \\
\left(\mu_{i, t}^{-}, \mu_{i, t}^{+}\right) \\
\sum_{i, t}^{\min } \leq p_{i, t} \leq p_{i, t}^{\max }, \forall i \in N_{B}, t \in N_{T},\left(\varsigma_{i, t}^{-}, \varsigma_{i, t}^{+}\right) \\
\sum_{t_{-} \leq t} A_{i, t, t_{-}} \hat{p}_{i, t_{-}}+u_{i, t} \leq K_{i, t}^{a, \max }, \forall i \in \mathrm{N}_{B}, \mathrm{t} \in N_{T}, \\
\left(\hat{\mu}_{i, t}^{-}, \hat{\mu}_{i, t}^{+}\right) \\
\hat{p}_{i, t}^{\min } \leq \hat{p}_{i, t} \leq \hat{p}_{i, t}^{\max }, \forall i \in N_{B}, t \in N_{T},\left(\hat{\zeta}_{i, t}^{-}, \hat{\zeta}_{i, t}^{+}\right)
\end{gathered}
$$

The Matrix $Z$ is the inverse matrix of the partial nodal admittance matrix $Y_{L L}$, which is a submatrix of the admittance matrix,

$$
Y=\left[\begin{array}{ll}
Y_{00} & Y_{0 L} \\
Y_{L 0} & Y_{L L}
\end{array}\right] .
$$

The DT is $\rho_{t}$, which is the congestion cost due to the potential congestions. The DT should always be non-negative. The following theorem is the key principle of the DT method which has been proven in [8] by comparing the KKT conditions of the optimization at the DSO side and the optimizations at the aggregator side.

Theorem 1: The sum of the optimal energy planning resulting from (1)-(5) of all aggregator is the same as the optimal energy planning resulting from (6)-(14) given that the regulation price $r_{t}$ (DT) is equal to $\rho_{t}$.

According to Theorem 1 , the DT, as a regulation price determined by the DSO using (6)-(14), is able to motivate the aggregators of the flexible demands (EVs and HPs) to make their schedule such that the network constraints are not violated. The DS, as another kind of regulation price, should be able to play the same role as the DT does. The method used by the
DSO to determine the proper DS is, however, quite different from the one to determine the DT. The DS is determined by a two-level optimization problem. The two-level optimization problem can be written as,

\section{Optimization I:}

$$
\min _{\mathrm{r}_{\mathrm{t}}, p_{i, t}, \hat{p}_{i, t}} \mathrm{~g}\left(r_{t}\right)=-\sum_{i \in N_{B}, t \in N_{T}} r_{t}^{T} E_{i}\left(p_{i, t}+\hat{p}_{i, t}\right)
$$

subject to (7) - (10),

$$
r_{t} \leq 0, \forall t \in N_{T},
$$

and

$$
\left(p_{i, t}, \hat{p}_{i, t}\right) \in \arg \min \{(1):(2)-(5)\}, \forall i \in N_{B} .
$$

The objective function $g$ represents the total cost of the DSO to employ the DS method (notice that $r_{t} \leq 0, \forall t \in N_{T}$ ). Constraint (16) requires the regulation price to be non-positive according to the definition of the DS. The inner optimization gives the outer optimization a constraint that the energy plan $\left(p_{i, t}, \hat{p}_{i, t}\right)$ must be the minimizer of (1) subject to (2)-(5), which represents the optimization problem of each aggregator. Finally, the energy plan $\left(p_{i, t}, \hat{p}_{i, t}\right)$ must fulfill constraints (7) (10). The Optimization I can be summarized as: the DSO needs to find the proper $r_{t}$ that minimizes the cost function $\mathrm{g}$, and $r_{t}$ is non-positive and the optimal energy plan of each aggregator with the given $r_{t}$ respects the network constraints (7) - (10). Therefore, Optimization I represents exactly the DS concept in subsection III.A.

It is obvious that the optimization result of each aggregator is the same as the optimal energy plan determined by Optimization I because it is assured by the inner optimization of Optimization I. Hence, the sum of all aggregators' energy planning respects the network constraints assured by constraints (7) - (10) of Optimization I. It implies that the decentralized congestion management through the DS method is realized.

\section{Feasibility Discussion and a Feasible Solution}

Optimization I is generally difficult to solve. Before trying to solve the problem, it is necessary to investigate its feasibility, i.e. whether there is any feasible solution and under what conditions there is. If the conditions under which the DS exists are too stringent, the DS method for congestion management will not be attractive to the DSO.

In the DT method, the DT exists as long as the optimization problem (6)-(14) is feasible, i.e. the feasible set determined by constraints (7)-(14) is not empty. The optimization problem (6)-(14) is a strictly convex problem and its feasible set is not infinite because of the constraints (12) and (14). Therefore, the optimization problem has an optimal solution as long as the feasible set is not empty. Hence, $\rho_{t}$ exists, i.e. the DT exists. Constraints (7)-(14) have defined the feasible condition for the DT method, i.e. there exists an energy plan respecting the network constraints as well as the requirements of each individual flexible demand.

It is desirable that the feasible condition for the DS method is as straightforward as the one for the DT method. It is possi- 
ble if the inner optimization of Optimization I is slightly modified and the base line price $c_{t}$ is strictly positive. Though the energy price is sometimes negative due to the excess production of renewable energy, the total base line price is usually positive. The modified inner optimization is,

$$
\begin{aligned}
& \min _{p_{i, t}, \hat{p}_{i, t}} \sum_{t \in N_{T}} \frac{1}{2} p_{i, t}{ }^{T}\left(\alpha B_{i, t}\right) p_{i, t}+\left(c_{t} \mathbf{1}+E_{i}^{T} r_{t}\right)^{T} p_{i, t} \\
&+\frac{1}{2} \hat{p}_{i, t}{ }^{T}\left(a B_{i, t}\right) \hat{p}_{i, t}+\left(c_{t} \mathbf{1}+E_{i}{ }^{T} r_{t}\right)^{T} \hat{p}_{i, t}
\end{aligned}
$$

subject to (2)-(5), where $\alpha$ is a small positive number $(0<\alpha \leq 1)$.

The coefficient $\alpha$ can be calculated through the following method. Firstly, the optimization problem (6)-(14) is solved and the Lagrange multiplier $\rho_{t}$ is found. Then the coefficient $\alpha$ is determined by,

$$
\alpha=\min \left\{\frac{c_{t}}{\left\{\rho_{t}\right\}_{j}+c_{t}} \mid \forall t \in N_{T}, j \in N_{d}\right\} .
$$

The new two-level optimization problem can be written as,

\section{Optimization II:}

(15) subject to (7) - (10), (16),

and $\left(p_{i, t}, \hat{p}_{i, t}\right) \in \arg \min \{(17):(2)-(5)\}, \forall i \in N_{B}$.

It can be proven that the regulation price,

$$
r_{t}=\alpha\left(\rho_{t}+c_{t} \mathbf{1}\right)-c_{t} \mathbf{1}, \forall t \in N_{T},
$$

is a feasible point of Optimization II; this implies that it is a feasible DS scheme which can re-profile the flexible demands such that the network constraints are respected.

Proof: Firstly, the regulation price $r_{t}$ determined by (19) is non-positive, because $\forall t \in N_{T}, j \in N_{d}$,

$$
\left\{r_{t}\right\}_{j}=\alpha\left(\left\{\rho_{t}\right\}_{j}+c_{t}\right)-c_{t} \leq \frac{c_{t}}{\left\{\rho_{t}\right\}_{j}+c_{t}}\left(\left\{\rho_{t}\right\}_{j}+c_{t}\right)-c_{t}=0 .
$$

Hence, constraint (16) is fulfilled.

Secondly, the inner optimization problem of Optimization II under the given $r_{t}$ has the same optimal solution as the optimization (1)-(5) with $r_{t}=\rho_{t}$. With the given $r_{t}$, the inner optimization problem can be rearranged as,

$$
\begin{gathered}
\min _{p_{i, t}, \hat{p}_{i, t}} \alpha\left(\sum_{t \in N_{T}} \frac{1}{2} p_{i, t}{ }^{T} B_{i, t} p_{i, t}+\left(c_{t} \mathbf{1}+E_{i}^{T} \rho_{t}\right)^{T} p_{i, t}\right. \\
\left.+\frac{1}{2} \hat{p}_{i, t}{ }^{T} B_{i, t} \hat{p}_{i, t}+\left(c_{t} \mathbf{1}+E_{i}^{T} \rho_{t}\right)^{T} \hat{p}_{i, t}\right)
\end{gathered}
$$

subject to (2)-(5). This is because,

$$
\begin{gathered}
c_{t} \mathbf{1}+E_{i}^{T} r_{t}=c_{t} \mathbf{1}+E_{i}^{T}\left(\alpha\left(\rho_{t}+c_{t} \mathbf{1}\right)-c_{t} \mathbf{1}\right) \\
=\alpha E_{i}^{T}\left(c_{t} \mathbf{1}+\rho_{t}\right)=\alpha\left(c_{t} \mathbf{1}+E_{i}^{T} \rho_{t}\right) .
\end{gathered}
$$

Assume that $\left(p_{i, t}{ }^{*}, \hat{p}_{i, t}{ }^{*}\right)$ is the optimal solution of (20) subject to (2)-(5), i.e. it is the minimizer of the inner optimization of Optimization II since they are equivalent to each other. Then, it is obviously also the optimal solution of (1)-(5) with $r_{t}=\rho_{t}$, because they have the same constraints and the proportional objective function with a constant factor $\alpha$.

Finally, according to Theorem $1,\left(p_{i, t}{ }^{*}, \hat{p}_{i, t}{ }^{*}\right)$ is also the op- timal solution of (6)-(14) since it is the optimal solution of (1) -(5) with $r_{t}=\rho_{t}$. Therefore, constraints (7) - (10) are fulfilled with $\left(p_{i, t}{ }^{*}, \hat{p}_{i, t}{ }^{*}\right)$. This leads to the conclusion that the regulation price determined by (19) is a feasible solution of Optimization II and its associated optimal energy plan is $\left(p_{i, t}{ }^{*}, \hat{p}_{i, t}{ }^{*}\right)$. (End of the proof)

It should be noted that in the DT method, the coefficient of the quadratic terms, i.e. $B_{i, t}$, is the sensitivity of the predicted energy price and plays the role of avoiding the degeneracy issue of the linear optimization problem when $B_{i, t}=0$. In the DS method, the coefficient of the quadratic terms becomes $\alpha B_{i, t}$ which is smaller than $B_{i, t}$ and its main function is to avoid the degeneracy issue. Parameter $\alpha B_{i, t}$ will be chosen to be sufficiently small such that it has the least impact on the energy planning.

\section{Method to Determine DS}

\section{A. Calculate DS with One-level Optimization}

Optimization II is to be solved in order to determine the efficient DS. Due to the strict convexity, the KKT conditions of the inner optimization problem are both necessary and sufficient. Hence, the inner optimization problem of Optimization II is equivalent to $\forall i \in N_{B}$,

$$
\begin{gathered}
\alpha B_{i} p_{i, t}+c_{t} 1+E_{i}^{T} r_{t}+\sum_{t_{-} \leq t}\left(\mu_{i, t_{-}}^{+}-\mu_{i, t_{-}}^{-}\right)+\left(\varsigma_{i, t}^{+}-\varsigma_{i, t}^{-}\right) \\
=0, \forall t \in N_{T} \\
\alpha B_{i} \hat{p}_{i, t}+c_{t} 1+E_{i}^{T} r_{t}+\sum_{t_{-} \leq t}\left(\hat{\mu}_{i, t_{-}}^{+}-\hat{\mu}_{i, t_{-}}^{-}\right)+\left(\hat{\zeta}_{i, t}^{+}-\hat{\zeta}_{i, t}^{-}\right) \\
=0, \forall t \in N_{T} \\
\left(\sum_{t_{-} \leq t}\left(p_{i, t_{-}}-d_{i, t_{-}}\right)+e_{i, 0}-e_{i}^{\max }\right) \cdot \mu_{i, t}^{+}=0, \forall \mathrm{t} \in \mathrm{N}_{T}, \\
\left(\sum_{t_{-} \leq t}\left(p_{i, t_{-}}-d_{i, t_{-}}\right)+e_{i, 0}-e_{i}^{\min }\right) \cdot \mu_{i, t}^{-}=0, \forall \mathrm{t} \in \mathrm{N}_{t}, \\
\left(p_{i, t}-p_{i, t}^{\max }\right) \cdot \varsigma_{i, t}^{+}=0, \forall t \in N_{T}, \\
\left(p_{i, t}-p_{i, t}^{\min }\right) \cdot \varsigma_{i, t}^{-}=0, \forall t \in N_{T}, \\
\left(\sum_{t_{-} \leq t} A_{i, t, t_{-}} \hat{p}_{i, t_{-}}+u_{i, t}-K_{i, t}^{a, \max }\right) \cdot \hat{\mu}_{i, t}^{+}=0, \forall \mathrm{t} \in N_{T}, \\
\left(\sum_{t_{-} \leq t} A_{i, t, t_{-}} \hat{p}_{i, t_{-}}+u_{i, t}-K_{i, t}^{a, \min }\right) \cdot \hat{\mu}_{i, t}^{-}=0, \forall \mathrm{t} \in N_{T}, \\
\left(\hat{p}_{i, t}-\hat{p}_{i, t}^{\max }\right) \cdot \hat{\zeta}_{i, t}^{+}=0, \forall t \in N_{T}, \\
\left(\hat{p}_{i, t}-\hat{p}_{i, t}^{\min }\right) \cdot \hat{\varsigma}_{i, t}^{-}=0, \forall t \in N_{T}, \\
\mu_{i, t}^{+}, \mu_{i, t}^{-}, \varsigma_{i, t}^{+}, \varsigma_{i, t}^{-}, \hat{\mu}_{i, t}^{+}, \hat{\mu}_{i, t}^{-}, \hat{\zeta}_{i, t}^{+}, \hat{\zeta}_{i, t}^{-} \geq 0, \forall i \in N_{B}, t \in N_{T}, \\
\text { and }(2)-(5) .
\end{gathered}
$$

Since the inner optimization problem is replaced with its KKT conditions, Optimization II is equivalent to a one-level optimization rewritten as,

\section{Optimization III:}

(15) subject to (16), (7) - (10) and $\forall i \in N_{B}$, (2)-(5) and (21) $-(31)$.

This one-level optimization is a nonlinear optimization and 
can be solved by many available commercial solvers. However, it is still hard to solve.

\section{B. Calculate DS with Tightened Constraints}

This section presents a linearized method to determine the DS by tightening the constraints. The feasible energy planning set resulting from the Optimization III's feasible set is tightened by assuming that the only allowed energy plan is $\left(p_{i, t}{ }^{*}, \hat{p}_{i, t}{ }^{*}\right)$, i.e. the optimal energy plan of (6)-(14). The reason is explained as follows. There are two costs associated with the customers. The first one is the energy cost (including the fixed cost) paid to the day-head market, grid companies and tax authorities, depending on the energy price and the energy plan. The second cost is the DS. Though it is an income in the congestion management, it will ultimately be a cost to the customers as explained in subsection III.A. The second cost is realized in a long term process. The DSO will adjust the grid tariffs depending on how much it spends on the DS in the last few months. Therefore, it is reasonable to separate these two costs. In the first step, the energy cost is minimized using (6)-(14), which will end up with the energy plan $\left(p_{i, t}{ }^{*}, \hat{p}_{i, t}{ }^{*}\right)$. Then, the DS will be minimized with the fixed energy plan, i.e. $\left(p_{i, t}{ }^{*}, \hat{p}_{i, t}{ }^{*}\right)$.

With a fixed energy plan, all the switching conditions become linear and the objective function becomes linear as well. The resulting liner optimization can be written as,

\section{Optimization IV:}

$$
\min _{r_{t}} g\left(r_{t}\right)=-\sum_{i \in N_{B}, t \in N_{T}} r_{t}^{T} E_{i}\left(p_{i, t}{ }^{*}+\hat{p}_{i, t}{ }^{*}\right)
$$

subject to (16), (21) - (31), where $p_{i, t}$ and $\hat{p}_{i, t}$ are fixed to

$$
\left(p_{i, t}^{*}, \hat{p}_{i, t}^{*}\right) \text {. }
$$

If coefficient $E_{i}\left(p_{i, t}{ }^{*}+\hat{p}_{i, t}{ }^{*}\right)$ becomes zero, $r_{t}$ becomes free. In practice, the following constraint can be added to avoid such a situation.

$$
r_{t} \geq-M E_{i}\left(p_{i, t}^{*}+\hat{p}_{i, t}^{*}\right)
$$

where coefficient $M$ is a very big number such that, when $E_{i}\left(p_{i, t}{ }^{*}+\hat{p}_{i, t}{ }^{*}\right)$ is nonzero, the constraint will have no effect on $r_{t}$. The procedure of calculating the DS can be summarized as: Employ (6)-(14) to determine $\left(p_{i, t}{ }^{*}, \hat{p}_{i, t}{ }^{*}\right)$ and $\rho_{t}$, then employ (18) to determine $\alpha$ and finally use Optimization IV to determine the DS.

\section{DISCUSSIONS OF DS AND DT}

\section{A. Limited DS and Unlimited DT}

Use the method proposed in Section IV.B, the calculated DS is always limited between zero and the maximum baseline price. The reason is explained as follows.

Same as the DT method, the DS method influence the behavior of the customers by changing the prices. The consumption of the flexible demands will be shifted from the hours with higher prices to the hours with lower prices. Without losing generality, consider a case with two hours. Assume hour $t_{1}$ has total price $c_{1}+r_{1}$ and hour $t_{2}$ has total price $c_{2}+r_{2}$. If the first price is sufficiently smaller than the second price, i.e. $c_{1}+r_{1} \ll c_{2}+r_{2}$, the energy consumption of the flexible demands will be shifted from hour $t_{2}$ to hour $t_{1}$, no matter the flexible demands have very efficient storage system like EVs or inefficient storage system like HPs. On the other hand, the total price cannot be zero or negative; otherwise, it will attract infinite large consumption of the flexible demands. Therefore, both prices are positive, i.e. $c_{1}+r_{1}>0$ and $c_{2}+r_{2}>0$. For the case of the DS, i.e. $r \leq 0$ and DS equals to $|r|$, there is $\left|r_{1}\right|<C_{1}$, and $\left|r_{2}\right|<C_{2}$. Therefore, the DS is always limited between zero and the maximum baseline price.

However, for the case of the DT, i.e. $r \geq 0$ and DT equals to $r$, the situation is in the opposite. In order to shift enough consumption from hour $t_{2}$ to hour $t_{1}$, the second price $c_{2}+r_{2}$ should be sufficiently large, which might lead to a very high $r_{2}$, i.e. a very high DT at hour $t_{2}$. This is verified in the case study in Section VI.B.

\section{B. Regulatory Issues}

In this subsection, the regulatory issue refers to the nondiscrimination requirement of the grid code [12]. This implies that customers in the same distribution network should have an equal opportunity to access the network, and the same type of customers should have same network tariffs. However, the DT method may not fulfil this requirement, because the customers located at different nodes may have different network tariffs. Therefore, unless this requirement is removed from the grid code, the DT method cannot be employed by the DSO.

For the DS method, the non-discrimination requirement is fulfilled. The network tariff is always the same for the same type of customers. The DS is given to those customers who are willing to shift their consumption in a way that benefits the network. After employing the DS method, the high energy prices become lower, and the customers who originally cannot consume cheap energies due to congestions are able to have the cheap prices like other customers who don't have congestion issues. In this sense, with the DS method, the customers have an equal and fair opportunity to access the network and the (cheap) energies. This will be further illustrated in subsection VI.B.

\section{Social Welfare}

With the method proposed in Section IV.B, the energy planning resulting from the DS method and the DT method is the same. Therefore, the social welfare from the supply side is the same in both methods.

The utility (benefits obtained from consuming energy) from the demand side is also the same in both methods, because the energy planning is the same. The cost at the demand side has two parts. The first part is the energy cost, which should be the same in both methods. The second part is the cost/reward due to the DT/DS. As the second part is a reallocation of money among the customers, the overall cost is zero 
for both methods. Therefore, the social welfare at the demand side is also the same for both methods. Hence, the social welfare using the DS method is the same as the one using the DT method.

\section{Linear Approximation of Power Flows in Distribution Networks}

The distribution network has two distinguishing features, namely the unbalanced three-phase loads and the high $\mathrm{R} / \mathrm{X}$ ratio of the lines, compared to the transmission network. The DT or DS concept is developed for congestion management of medium voltage (MV) distribution networks. In most cases, the MV distribution networks are balanced networks. All the loads and the flexible demands from one load point are aggregated and considered as a lump load connected to the low voltage (LV) transformer. The LV transformers are considered as load points in the load flow analysis. In the future work, the application of the DT or DS method for congestion management of unbalanced distribution networks will be studied.

The high $\mathrm{R} / \mathrm{X}$ ratio affects the accuracy of the DCOPF model for distribution networks. One concern is the active power losses of the distribution networks, because the active power losses should be negligible according to the assumption of the DCOPF. However, this concern can be relieved and explained as follows. It is reported that the total line losses are marginal for many developed countries [23], e.g. China 6\%, Denmark 6\%, France 7\% and the USA 6\%. The active power losses in distribution networks will be even smaller and can be neglected.

The second concern is the (low) power factor due to reactive power consumptions and losses. This concern can also be relieved. Because the $\mathrm{R} / \mathrm{X}$ ratio is higher than one on $\mathrm{MV}$ feeders, the reactive power losses of MV feeders will be even smaller than the active power losses. It is reported in [24] that the reactive power losses of typical distribution transformers are about $7 \%$ of the apparent power flowing, which are also fairly small. The reactive power does not affect the DCOPF accuracy directly; however, it affects the ratio of the active power to the apparent power, i.e. the power factor, and affects the line loading limit constraint (7). The line loading limit is normally determined by the apparent power. Therefore, the active power limit $F_{t}$ should be corrected according to the average power factor. For instance, it should be $10 \%$ less than the apparent power limit if the average power factor of the loads is 0.9 . The DSO should set the line loading limits according to the estimated average power factor. High power factor makes the DCOPF more accurate and the power losses smaller, which will in turn benefit the DSO. The power factor can be improved by installing reactive power compensators or having reactive power support from EVs or smart transformers [25].

The third concern due to the high $\mathrm{R} / \mathrm{X}$ ratio is that the voltage drops are not negligible, especially for long distance feeders. The authors of [22] have proposed a linear approximation method to calculate the voltages based on the power consumptions at each load point. This method is adopted in this paper, and the voltage limits are taken into account by (8).

\section{E. Stochastic Nature of the Flexible Demands}

The model for determining the DT or the DS is deterministic and doesn't take into account the stochastic nature of the flexible demands. For instance, the EVs are modelled by their expected energy demands and the expected arriving and leaving times. The deterministic model has the following advantages: It is easier to understand the concept of the DT or the DS method with a simple and clear model; The DSO can have a quick overview of where and how heavy the congestions are in the network based on the average model of the flexible demands; the DSO can choose to use the worst scenario of the flexible demands for the DT or the DS method and has a sufficient safety margin in the distribution network.

On the other hand, the DSO may want to manage the uncertainties of the congestions due to the stochastic flexible demands, in addition to the abovementioned average model case and the worst scenario case. It should be pointed out that, in the business model of the DT or the DS method for congestion management, the focus is given to the DSO side. The DSO determines the DT or the DS through an optimal energy planning based on predicted data of the flexible demands and the conventional demands. How the aggregator will interact with its customers in the real-time operations/controls depends on the contract type made between the aggregator and its customers, and it is not a focus of the DT or the DS method. However, it is assumed that the aggregators are rational and use optimization methods to make energy planning and control for its customers.

In [26], it is possible to determine the DTs using the deterministic method, such that the possibility of congestions is less than a predefined level based on the statistical feature of the predicted data of the flexible demands. Since only the MV network is considered and it is assumed that there are many flexible demands connected to a load point ( $\mathrm{LV}$ transformer) as mentioned in Subsection V.D, there is enough diversity of the stochastic flexible demands at each load point. This feature helps the statistical analysis of the flexible demands at each load point. The fundamental idea of the uncertainty management proposed in [26] is to iteratively reduce the line loading limits and perform the statistics analysis of the congestions based on the statistical feature of the predicted data, until the possibility of congestions is less than a predefined level. The deterministic model is employed in each iteration step. The final line loading limits determined in the iterative method can be used to determine the DS through the method proposed in this paper. Consequently, the DS determined in this way is able to influence the flexible demands such that the possibility of congestions is less than a predefined level.

\section{CAse Studies}

\section{A. Case Study with a One Node System}

In order to illustrate the idea and efficacy of the DS method for congestion management, a straightforward case was studied first. Only one EV is considered which requires $4 \mathrm{kWh}$ for 
its battery. The network constraint is the fuse outside the household, which gives a limit of $4 \mathrm{~kW}$. Considering the basic load of $1 \mathrm{~kW}$ for each period, the allowed capacity for the EV charging is only $3 \mathrm{~kW}$. Only three charging periods are considered and the predicted energy prices are $0.5,0.2,0.6$ $\mathrm{DKK} / \mathrm{kWh}$, respectively (the fixed cost is neglected).

1) DT method:

The DT method was studied first which can not only give a comparison with the DS method but also offer some useful results needed by the DS method. The DSO solves the following optimization problem first in order to determine the DTs.

$$
\min _{p_{t}} \sum_{1 \leq t \leq 3} \frac{1}{2} \beta p_{t}^{2}+c_{t} p_{t}
$$

subject to,

$$
\begin{gathered}
p_{t} \leq 3, t=1,2,3 \\
\sum_{1 \leq t \leq 3} p_{t} \geq 4 \\
p_{t} \geq 0, t=1,2,3
\end{gathered}
$$

Constraint (35) assures the limit of the fuse, (36) reflects the energy requirement and (37) implies no discharging. The calculated DTs, which in this case are Lagrange multipliers of (35), are $0.2996 \mathrm{DKK} / \mathrm{kWh}$ for period 2 and zero for other periods (see Table I). The DTs will be sent to the aggregator who will make an optimal energy planning for the EV by the following optimization.

$$
\min _{p_{t}} \sum_{1 \leq t \leq 3} \frac{1}{2} \beta p_{t}^{2}+\left(c_{t}+r_{t}\right) p_{t},
$$

subject to (36)-(37). The results are listed in Table I (row “ $p_{t}(\mathrm{~kW})$ - with DT”).

2) DS method:

In order to calculate the DS, the DSO formulates the following two-level optimization according to Optimization II, where $\alpha$ is determined to be 0.4003 (Table I - row “ $\alpha$ ”) according to (18).

$$
\min _{r_{t}, p_{t}} \sum_{1 \leq t \leq 3}-r_{t} p_{t}
$$

subject to (35),

$$
p_{t} \in \arg \min \left\{\sum_{1 \leq t \leq 3} \frac{1}{2} \alpha \beta p_{t}^{2}+\left(c_{t}+r_{t}\right) p_{t}:\right.
$$

(36)-(37)\}.

The above two-level optimization is difficult to solve directly, and therefore is transformed to the following one-level optimization according to Optimization III.

$$
\begin{gathered}
\text { (39) subject to (35), (36)-(37), } \\
\alpha \beta p_{t}+c_{t}+r_{t}-\mu-\varsigma_{t}=0, t=1,2,3, \\
\left(\sum_{1 \leq t \leq 3} p_{t}-4\right) \mu=0, \\
p_{t} \varsigma_{t}=0, t=1,2,3, \\
\mu \geq 0, \varsigma_{t} \geq 0, t=1,2,3 .
\end{gathered}
$$

Though the above nonlinear optimization can be solved, it is desirable to transform it to a linear problem by fixing $p_{t}$ according to Optimization IV. The final linear formulation is obtained as below.

(39) subject to (40), (43),

$$
\varsigma_{t}=0, t=1,2 .
$$

where the 'parameter' $p_{t}$ takes the value $p_{t}{ }^{*}=(1,3,0)$. The final optimal DS is obtained by solving the above linear program using General Algebraic Modeling System (GAMS) [17] and the results are list in Table I (row "DS-2 (DKK/kW)" and " $p_{t}(\mathrm{~kW})$ - with DS"). A feasible DS is directly calculated according to (19) and listed in Table I as well (row "DS-1 (DKK/kW)"), which is not as efficient as the optimal DS because the DS for $t=3$ has no effect on the EV charging planning and therefore should be zero. Though both of the DS sets can motivate the aggregator to make an optimal plan which respects the network constraint, only the optimal DS should be chosen by the DSO.

\section{B. Case Study with the Bus 4 Distribution Network of RTBS}

\section{1) Case study parameters:}

The single line diagram of the Bus 4 distribution network of the Roy Billinton Test System (RBTS) [27] is shown in Fig. 1. Line segments of the feeder one are labeled in Fig. 1, among which L2, L4, L6, L8, L9, L11, and L12 refer to the transformers connecting the corresponding load points (LP1 to LP7). The study is focused on this feeder because it has the most diversity among all the feeders: 5 residential load points with different peak conventional demands and two commercial load points. The detailed data of these load points are listed in Table II. The peak conventional demands of residential customers are assumed to occur at 18:00 when people arrive home and start cooking. Assume that the EVs and HPs have unit power factor. The DSO has improved the power factor of the conventional consumption by reactive power compensations, and the remaining reactive power consumption is $10 \%$ of the conventional active power consumption. The line parameters are shown in Table III.

The key parameters of the simulation are listed in Table IV. The lower voltage limit is set to be 0.948 p.u., in order to have a small margin (0.006 0.008 p.u.) compared to the assumed physical limit 0.94 p.u. The EV availability shown in Fig. 2 is from the driving pattern study in [28]. The household area is a random number between 100 and $200\left(\mathrm{~m}^{2}\right)$.

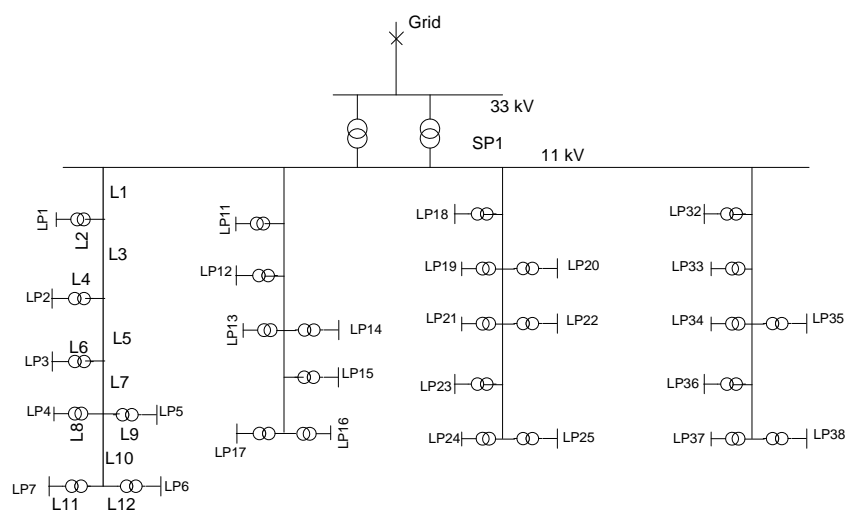

Fig. 1. Single line diagram of the distribution network 
PARAMETERS AND RESUltS OF THE SiMPLE EXAMPLE

\begin{tabular}{|c|c|c|c|}
\hline time & 1 & 2 & 3 \\
\hline$\beta(\mathrm{DKK} / \mathbf{k W} / \mathbf{k W})$ & \multicolumn{3}{|l|}{0.0002} \\
\hline$C_{t}(\mathrm{DKK} / \mathbf{k W})$ & 0.5 & 0.2 & 0.6 \\
\hline DT $(\mathrm{DKK} / \mathbf{k W})$ & 0 & 0.2996 & 0 \\
\hline$p_{t}(\mathbf{k W})-$ with $\mathbf{D T}$ & 1 & 3 & 0 \\
\hline$\alpha$ & \multicolumn{3}{|c|}{$0.2 /(0.2+0.2996)=0.4003$} \\
\hline DS-1 (DKK/kW) & -0.2999 & 0 & -0.3598 \\
\hline DS-2 (DKK/kW) & -0.29992 & 0 & 0 \\
\hline$p_{t}(\mathbf{k W})-$ with DS & 1 & 3 & 0 \\
\hline
\end{tabular}

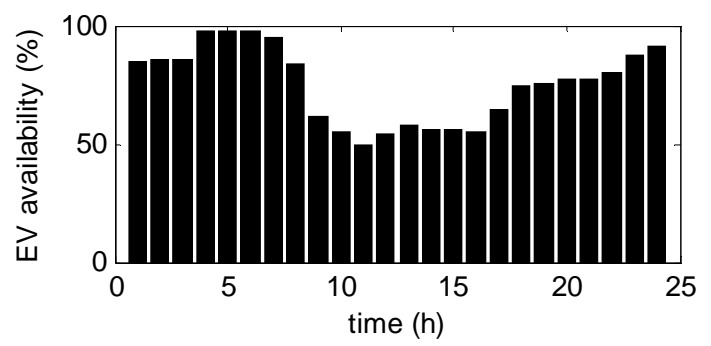

Fig. 2. EV availability

TABLE II

LOAD POINT DATA

\begin{tabular}{lllll}
\hline $\begin{array}{c}\text { load } \\
\text { points }\end{array}$ & $\begin{array}{c}\text { customer } \\
\text { type }\end{array}$ & $\begin{array}{c}\text { peak conv. } \\
\text { act. power } \\
\text { per point } \\
(\mathbf{k W})\end{array}$ & $\begin{array}{c}\text { peak conv. } \\
\text { react. power } \\
\text { per point } \\
\text { (kVar) }\end{array}$ & $\begin{array}{c}\text { number } \\
\text { of cus- } \\
\text { tomers } \\
\text { per point }\end{array}$ \\
\hline LP1-LP4 & residential & 886.9 & 88.69 & 200 \\
\hline LP5 & residential & 813.7 & 81.37 & 200 \\
\hline LP6,LP7 & commercial & 671.4 & 67.14 & 10 \\
\hline
\end{tabular}

TABLE III

LINE PARAMETERS

\begin{tabular}{llll}
\hline Line & $\mathbf{r}(\mathbf{o h m})$ & $\mathbf{x}(\mathbf{o h m})$ & $\mathbf{x} / \mathbf{r}$ ratio \\
\hline 1 & 0.1210 & 0.0370 & 0.3058 \\
\hline 2 & 0.3000 & 3.0000 & 10.0000 \\
\hline 3 & 0.4233 & 0.0943 & 0.2228 \\
\hline 4 & 0.3000 & 3.0000 & 10.0000 \\
\hline 5 & 0.3722 & 0.0829 & 0.2227 \\
\hline 6 & 0.3000 & 3.0000 & 10.0000 \\
\hline 7 & 0.4403 & 0.0981 & 0.2228 \\
\hline 9 & 0.3000 & 3.0000 & 10.0000 \\
\hline 10 & 0.3000 & 3.0000 & 10.0000 \\
\hline 11 & 0.3091 & 0.0689 & 0.2229 \\
\hline 12 & 0.3000 & 3.0000 & 10.0000 \\
\hline
\end{tabular}

\section{2) Case study results}

The simulation was carried out using the GAMS optimization software [30].

Firstly, the DT calculation was conducted. The DSO optimization problem with network constraints was solved and the optimal energy plan was found. The line loadings of L2, L3 and L4 with the DT method are shown in Fig. 3. Because the line loading limits are respected in the optimization, the line loadings of all line segments are lower than the limits. As the voltage constraints are also included in the optimization, the voltage profile of the critical bus, LP4, is shown in Fig. 4 and is above the lower voltage limit. The base energy prices and the final energy prices with the DT for the customers at LP1 are shown in Fig. 5. The DTs at LP4 and LP5 are shown in Table V.

TABLE IV

Key Parameters of the Simulation Model ([28], [29])

\begin{tabular}{ll}
\hline \multicolumn{1}{c}{ parameter } & \multicolumn{1}{c}{ value } \\
\hline EV battery size & $25 \mathrm{kWh}$ \\
\hline Peak charging power & $11 \mathrm{~kW}(3$ phase $)$ \\
\hline Energy consumption per $\mathrm{km}$ & $150 \mathrm{Wh} / \mathrm{km}$ \\
\hline Minimum SOC & $20 \%$ \\
\hline Maximum SOC & $85 \%$ \\
\hline Average driving distance & $40 \mathrm{~km}$ \\
\hline COP of HP & 2.3 \\
\hline Min Temp. of the House & $20^{\circ} \mathrm{C}$ \\
\hline Max Temp. of the House & $24{ }^{\circ} \mathrm{C}$ \\
\hline Voltage rating $=V_{0}$ & $11 \mathrm{kV}$ \\
\hline Lower voltage limit & $0.948 \mathrm{p.u}$. \\
\hline Transformer rating & $1 \sim 3 \mathrm{MVA}$ \\
\hline L2 limit $(\mathrm{kW})$ & 1100 \\
\hline L3 limit $(\mathrm{kW})$ & 7000 \\
\hline L4 limit $(\mathrm{kW})$ & 2700 \\
\hline
\end{tabular}

Secondly, the DS calculation was done using Optimization IV. The resulting prices (the base energy price minus the DS) for the customers at LP1 are also shown in Fig. 5. The DS is nonzero for many time periods for LP1 because the limit of L2 is tight. Therefore, many nonzero DSs are needed to re-profile the flexible demands such that the line loading limit is respected. The DSs at LP4 and LP5 are also shown in Table V along with the DTs.

Then, the DS method was verified by sending the DSs to the aggregators. Each aggregator performed the optimization (1)-(5) and ended up with a total energy plan as shown in Fig. 6 . As a comparison, the total energy plan resulting from the DT method is also shown in Fig. 6. The voltage profile of LP4 is plotted in Fig. 4. Though there are small discrepancies, such as L3 loadings at hour 15/16 and LP 4 voltages at hour 15-19, the overall load and voltage profiles resulting from the DT and DS methods are consistent. The discrepancies are due to the precision limits of the optimization solver. The accuracy of the voltage approximation method is quite high because the error is less than $0.5 \%$ as shown in Fig. 4 . The accurate voltage profile does not violate the physical limit 0.94 p.u. because of the margin set before.

3) Discussion:

It can be observed from Fig. 4 that the final energy prices with the DS are always between zero and the base energy prices. Therefore, the DS is always limited between zero and the base energy prices, as it is the difference between the final energy price and the base energy price. In Fig. 4, it can be seen that the DT is always positive and can be very high. For instance, the maximum DT is about 0.709 (DKK/kWh) at hour 19, which is almost twice of the maximum base price. However, the maximum DS (absolute value) is only 0.27 (DKK/kWh) at hour 16 . This is because the price difference 
determines the optimal energy plan, not the absolute value of the prices. Take LP1 as an example. In order to shift the HP demand from hour 19 to hour 16, the price at hour 19 should be several times higher than hour 16 in the DT method. However, in order to shift the same amount of the HP demand, the price at hour 16 needs to be several times lower than hour 19 . This results in a very high DT, but a moderate DS.

Moreover, receiving DS gives the customers a fair opportunity to the low energy prices. Take LP1 as an example. A customer wants to charge his EV in hour 24, because the energy price is lower. However, due to the congestion, he is forced to charge his EV partially in hour 23 with a higher price. With the DS, he can charge his EV in hour 23 with an equally cheap price in hour 24 . This gives the customer the same opportunity to utilize the cheap energy price just as the customers at the load points where there are no congestions, such as LP11.

At last, it is obvious that there is no rebound effect with the DS (or the DT) method, because the optimization is conducted over the whole time period corresponding to the day-ahead energy market.
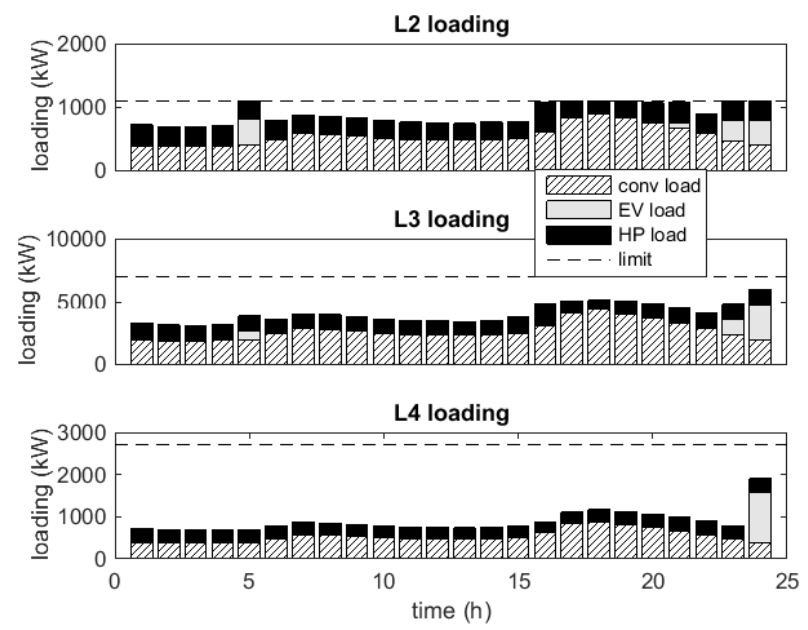

Fig. 3. Line loading with the DT method

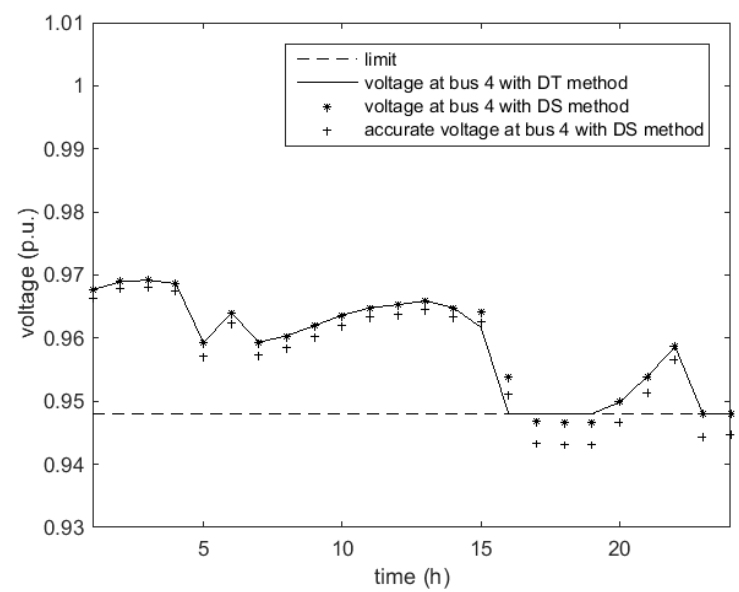

Fig. 4. Voltage profile of LP4; the accurate voltage profile was obtained by load flow analysis and the error between the approximate voltage and the accurate one is less than $0.5 \%$

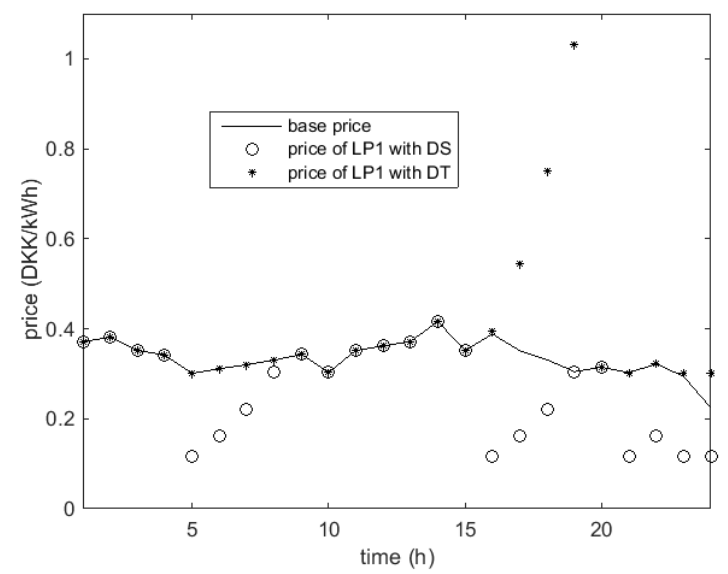

Fig. 5. System prices (base price) and final prices (including DT or DS) at LP1
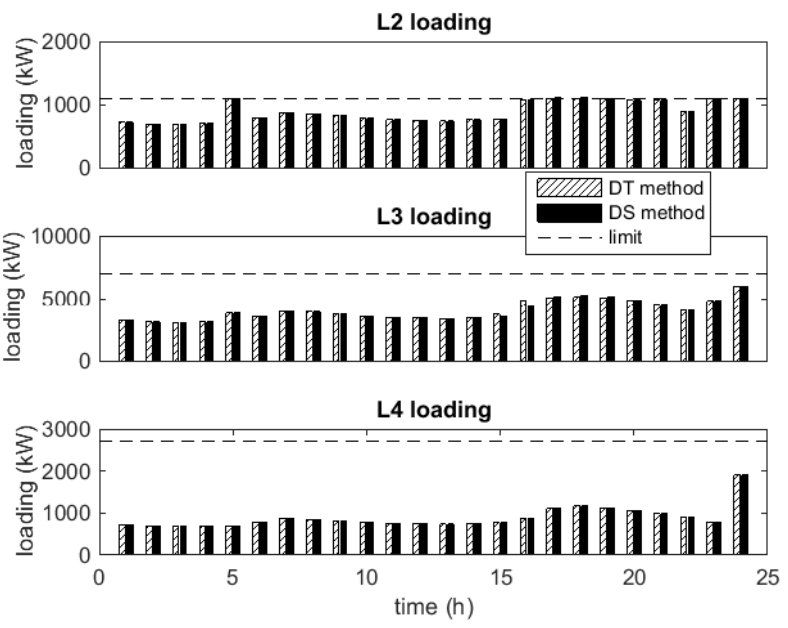

Fig. 6 Line loading profiles resulting from the DT and DS methods

TABLE V

PRICES (DKK/KWH) FOR LP4-5 (OTHER HOURS ARE ALL ZERO)

\begin{tabular}{|r|r|r|r|r|}
\hline & \multicolumn{2}{|c|}{ DT } & \multicolumn{2}{c|}{ DS } \\
\hline \multicolumn{1}{|c|}{ Time } & \multicolumn{1}{|c|}{ LP04 } & \multicolumn{1}{c|}{ LP05 } & \multicolumn{1}{c|}{ LP04 } & \multicolumn{1}{c|}{ LP05 } \\
\hline 5 & 0 & 0 & -0.21642 & -0.12642 \\
\hline 6 & 0 & 0 & -0.1945 & -0.0706 \\
\hline 7 & 0 & 0 & -0.15959 & 0 \\
\hline 8 & 0 & 0 & -0.10909 & 0 \\
\hline 9 & 0 & 0 & -0.03873 & 0 \\
\hline 15 & 0 & 0 & -0.26677 & 0 \\
\hline 16 & 0.09541 & 0.07814 & -0.27171 & -0.21362 \\
\hline 17 & 0.31531 & 0.29106 & -0.1905 & -0.11064 \\
\hline 18 & 0.58645 & 0.55307 & -0.10993 & 0 \\
\hline 19 & 0.95859 & 0.78502 & & 0 \\
\hline 23 & 0.00691 & 0.00681 & -0.20943 & -0.11946 \\
\hline 24 & 0.07713 & 0.07702 & -0.13938 & -0.0494 \\
\hline
\end{tabular}

\section{CONCLUSIONS}

This paper proposes the DS method for congestion management in distribution networks with high penetration of EVs and HPs. The DS method employs a decentralized framework to realize the congestion management. A two level optimization formulation is proposed to determine the DS. By using the KKT conditions of the inner optimization, the two level 
optimization of calculating the DS is transformed into a one level optimization. By tightening the feasible set, the optimization is further simplified and easier to be solved. The case studies have demonstrated the DS method and validated its efficacy for congestion management.

Though it takes more efforts to determine the DS than the DT, the DS method is preferred to the DT method for congestion management nowadays. The DS does not have any regulatory issue. It provides a fair opportunity to customers to access the cheap energy prices. Moreover, it does not have the rebound effect. In the future, it will be interesting to compare the long term cost, e.g. the grid reinforcement, and the cost of DS. A co-optimization may be utilized to find the breaking point of these two costs.

\section{APPENDIX}

In this appendix, constraint (4) is derived. The full version of the derivation can be found in [8]. The heat transfer process of the air source HP can be represented by an electric circuit [31] which is illustrated in Fig. 7. Thus, the following thermal balance equations can be derived [31].

$$
\begin{gathered}
Q_{t}^{e}+S_{t}^{1}-k_{1}\left(K_{t}^{a}-K_{t}\right)-k_{2}\left(K_{t}^{a}-K_{t}^{s}\right)= \\
C_{a}\left(K_{t}^{a}-K_{t-1}^{a}\right), \forall \mathrm{t} \in N_{T} \\
S_{t}^{2}+k_{2}\left(K_{t}^{a}-K_{t}^{s}\right)-k_{3}\left(K_{t}^{s}-K_{t}\right)= \\
C_{s}\left(K_{t}^{s}-K_{t-1}^{s}\right), \forall \mathrm{t} \in N_{T}
\end{gathered}
$$

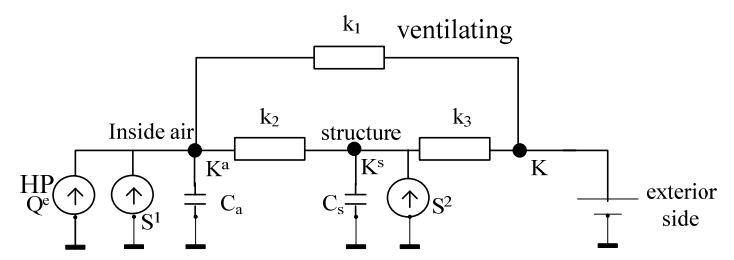

Fig. 7. Heat transferring process of the house

Equations (45) and (46) can be solved iteratively. As a result, the house inside air temperature $K_{t}^{a}$ will be a linear combination of all the previous and the current thermal energy ( $Q_{t}^{e}$ ) plus an initial state. Because $Q_{t}^{e}$ has a linear relation (by the coefficient of performance (COP)) to the active power $\hat{p}_{t}$ consumed by the HP, the house inside air temperature can be expressed as,

$$
K_{t}^{a}=\sum_{t_{-} \leq t} a_{t, t_{-}} \hat{p}_{t_{-}}+u_{t} \quad \forall \mathrm{t} \in N_{T}
$$

Finally, the matrix form for (47) is written as,

$$
K_{i, t}^{a, \min } \leq \sum_{t_{-} \leq t} A_{i, t, t_{-}} \hat{p}_{i, t_{-}}+u_{i, t} \leq K_{i, t}^{a, \max }, \forall i \in \mathrm{N}_{B}, \mathrm{t} \in N_{T}
$$

where $A_{i, t, t_{-}} \in R^{m_{i} \times m_{i}}$ is a diagonal matrix.

\section{REFERENCES}

[1] S. Huang, Q. Wu, Z. Liu, and A. H. Nielsen,"Review of congestion management methods for distribution networks with high penetration of distributed energy resources,” in Proc. 2014 IEEE PES Innovative Smart Grid Technologies, Europe, pp. 1-6.
[2] M. Pipattanasomporn, H. Feroze, and S. Rahman,“Multi-agent systems in a distributed smart grid: Design and implementation,” in Proc. 2009 IEEE/PES Power Systems Conference and Exposition, pp. 1-8.

[3] M. H. Amini, B. Nabi, and M.-R. Haghifam, "Load management using multi-agent systems in smart distribution network,” in Proc. 2013 IEEE Power \& Energy Society General Meeting, pp. 1-5.

[4] M. Esmaili, N. Amjady, and H. A. Shayanfar,"Stochastic congestion management in power markets using efficient scenario approaches," Energy Convers. Manag., vol.51, no.11, pp. 2285-2293, 2010.

[5] M. Hojjat and M. H. Javidi D. B.,"Probabilistic congestion management considering power system uncertainties using chance-constrained programming,” Electr. Power Components Syst., vol.41, no.10, pp. 972989, Jul. 2013.

[6] N. O’Connell, Q. Wu, J. Østergaard, A. H. Nielsen, S. T. Cha, and Y. Ding, "Day-ahead tariffs for the alleviation of distribution grid congestion from electric vehicles,” Electr. Power Syst. Res., vol.92, pp. 106-114, 2012.

[7] R. Li, Q. Wu, and S. S. Oren,"Distribution locational marginal pricing for optimal electric vehicle charging management," IEEE Trans. Power Syst., vol.29, no.1, pp. 203-211, Jan. 2014.

[8] S. Huang, Q. Wu, S. S. Oren, R. Li, and Z. Liu,“Distribution locational marginal pricing through quadratic programming for congestion management in distribution networks,” IEEE Trans. Power Syst., vol.30, no.4, pp. 2170-2178, Jul. 2015.

[9] S. Huang, Q. Wu, L. Cheng, and Z. Liu,“Optimal Reconfiguration-Based Dynamic Tariff for Congestion Management and Line Loss Reduction in Distribution Networks,” IEEE Trans. Smart Grid, vol.7, no.3, pp. 12951303, May 2016.

[10] P. M. Sotkiewicz and J. M. Vignolo,"Nodal pricing for distribution networks: Efficient pricing for efficiency enhancing DG,” IEEE Trans. Power Syst., vol.21, no.2, pp. 1013-1014, May 2006.

[11] G. T. Heydt, B. H. Chowdhury, M. L. Crow, D. Haughton, B. D. Kiefer, F. Meng, and B. R. Sathyanarayana,"Pricing and control in the next generation power distribution system," IEEE Trans. Smart Grid, vol.3, no.2, pp. 907-914, Jun. 2012.

[12] EU Comission. (2015, Jan. ). Study on tariff design for distribution systems. [online]. Available: https://ec.europa.eu/energy/sites/ener/files/documents/20150313 Tariff report fina_revREF-E.PDF.

[13] Z. Fan, “A distributed demand response algorithm and its application to PHEV charging in smart grids,” IEEE Trans. Smart Grid, vol.3, no.3, pp. 1280-1290, Sep. 2012.

[14] F. Kamyab, M. Amini, S. Sheykhha, M. Hasanpour, and M. M. Jalali,"Demand response program in smart grid using supply function bidding mechanism,” IEEE Trans. Smart Grid, vol.7, no.3, pp. 12771284, May 2016.

[15] J. Mohammadi, H. Ghasemi, J. Saebi, and M. K. Sheikh-elEslami,"Using responsive loads as a tool for congestion management and system loss reduction,” in Proc. 2010 IEEE International Energy Conference, pp. 797-801.

[16] M. R. Sarker, M. A. Ortega-Vazquez, and D. S. Kirschen,“Optimal coordination and scheduling of demand response via monetary incentives,” IEEE Trans. Smart Grid, vol.6, no.3, pp. 1341-1352, May 2015.

[17] H. Zhong, L. Xie, and Q. Xia,"Coupon incentive-based demand response: theory and case study,” IEEE Trans. Power Syst., vol.28, no.2, pp. 1266-1276, May 2013.

[18] C. Zhang, Y. Ding, N. Nordentoft, P. Pinson, and J. Østergaard,"FLECH-A danish market solution for DSO congestion management through DER flexibility services,” J. Mod. Power Syst. Clean Energy, vol.2, no.2, pp. 126-133, 2014.

[19] Shaojun Huang, Qiuwei Wu, Zhaoxi Liu, and Haoran Zhao,"Sensitivity analysis of dynamic tariff method for congestion management in distribution networks,” in Proc. 2015 IEEE Power \& Energy Society General Meeting, pp. 1-6.

[20] M. H. Amini and A. Islam,“Allocation of electric vehicles’ parking lots in distribution network," in Proc. 2014 Innovative Smart Grid Technologies Conference (ISGT), pp. 1-5.

[21] C. Li, J. Zhou, Y. Cao, J. Zhong, Y. Liu, C. Kang, and Y. Tan, "Interaction between urban microclimate and electric airconditioning energy consumption during high temperature season," Appl. Energy, vol.117, pp. 149-156, 2014. 
[22] S. Bolognani and S. Zampieri,“On the existence and linear approximation of the power flow solution in power distribution networks,” IEEE Trans. Power Syst., vol.31, no.1, pp. 163-172, Jan. 2016.

[23] IEA Statistics, "Electric power transmission and distribution losses (\% of output)," $2014 . \quad$ Available: http://data.worldbank.org/indicator/EG.ELC.LOSS.ZS. [Accessed: 02May-2016].

[24] Schneider Electric. (2016). Electrical Installation Guide. Online: http://www.schneider-electric.com/b2b/en/products/productlaunch/electrical-installation-guide/.

[25] S. Huang, J. R. Pillai, M. Liserre, and B. Bak-Jensen,"Improving photovoltaic and electric vehicle penetration in distribution grids with smart transformer," in Proc. 2013 4th IEEE/PES Innovative Smart Grid Technologies Europe, ISGT Europe 2013, pp. 1-5.

[26] S. Huang, Q. Wu, L. Cheng, Z. Liu, and H. Zhao,"Uncertainty management of dynamic tariff method for congestion management in distribution networks,” IEEE Trans. Power Syst., in press.

[27] R. N. Allan, R. Billinton, I. Sjarief, L. Goel, and K. S. So,“A reliability test system for educational purposes-basic distribution system data and results,” IEEE Trans. Power Syst., vol.6, no.2, pp. 813-820, May 1991.

[28] Q. Wu, A. H. Nielsen, J. Østergaard, F. Marra, and C. Træholt,“Driving pattern analysis for electric vehicle (EV) grid integration study," in Proc. 2010 IEEE PES Innovative Smart Grid Technologies Conference Europe (ISGT Europe), pp. 1-6.

[29] J. M. Nyers and A. J. Nyers, “COP of heating-cooling system with heat pump," in Proc. IEEE 3rd International Symposium on Exploitation of Renewable Energy Sources (EXPRES), pp. 17-21.

[30] R. E. Rosenthal. (2014, Aug. ). GAMS - A user's guide. GAMS Development Corporation, Washington, DC, USA. [online]. Available: http://www.gams.com/dd/docs/bigdocs/GAMSUsersGuide.pdf.

[31] P. Bacher and H. Madsen,"Identifying suitable models for the heat dynamics of buildings,” Energy Build., vol.43, no.7, pp. 1511-1522, Jul. 2011.

\section{BIOGRAPHIES}

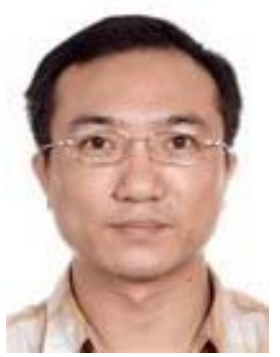

Shaojun Huang (S'13) obtained the B. Eng. from Department of Electrical Engineering, Tsinghua University, Beijing, P. R. China, in 2001. He obtained the MSc from Department of Energy Technology, AAlborg University, Denmark, in 2013. Currently, he is pursuing his $\mathrm{PhD}$ degree in Centre for Electric Power and Energy, Department of Electrical Engineering, Technical University of Denmark.

His research interests are congestion management for distribution networks with high penetration of distributed energy resources.

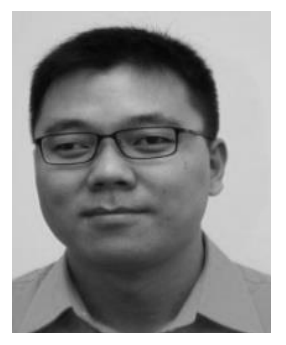

Qiuwei Wu (M'08-SM'15) obtained the B. Eng. and M. Eng. from Nanjing University of Science and Technology, Nanjing, P. R. China, in 2000 and 2003, respectively, both in Power System and Its Automation. He obtained the $\mathrm{PhD}$ degree from Nanyang Technological University, Singapore, in 2009, in Power System Engineering.

He was a senior R\&D engineer with VESTAS Technology R\&D Singapore Pte Ltd from Mar. 2008 to Oct. 2009. He has been working at Department of Electrical Engineering, Technical University of Denmark (DTU) since Nov. 2009 (PostDoc Nov. 2009-Oct. 2010, Assistant Professor Nov. 2010-Aug. 2013, Associate Professor since Sept. 2013). He was a visiting scholar at Department of Industrial Engineering \& Operations Research (IEOR), University of California, Berkeley from Feb. 2012 to May 2012 funded by Ministry of Science, Technology and Innovation, Denmark. He is also a visiting professor named by Y. Xue, an Academician of Chinese Academy of Engineering, at Shandong University, China.

His research interests are integration of wind power and electric vehicle into power systems, active distribution networks, and real time power system simulation and analysis. He is an Editor of IEEE Transactions on Smart Grid and IEEE Power Engineering Letters. He is also an Associate Editor of International Journal of Electrical Power and Energy Systems. 